\title{
Assessment of Occlusal Characteristics in Primary Dentition of Preschool Children in Amritsar, Punjab, India
}

\author{
${ }^{1}$ Gunmeen Sadana, ${ }^{2}$ Manjul Mehra, ${ }^{3}$ Rashu Grover, ${ }^{4}$ Sunil Gupta, ${ }^{5}$ Ankita Bhargawa
}

\begin{abstract}
Background: The occlusal relationship and spacing in deciduous dentition are known to have an imperative demeanor on the setting up of the normal occlusal relationship in permanent dentition. The attribute set of features of this dentition acts as a mirror for the prevalence of malocclusion in the permanent dentition. The properly placed teeth in the dental arch not only uphold the health of the oral cavity and the supporting structures but also sway the persona of the children.
\end{abstract}

Aims and objectives: The objective of this study is to assess the characteristic features of occlusion in primary dentition (spacing, molar, and canine relation) among the urban and rural preschool children of Amritsar.

Materials and methods: Preschool children 3-5 years of age having the complete set of deciduous teeth were included in the study. Informed consent for the child's participation was taken from their parents and school principal. The dentition was examined under natural daylight, and the data was recorded. All the school children were screened for spaced and non-spaced dentition, molar, and canine relationship according to Foster and Hamilton criteria (1969). The data will be compared and analyzed.

Results: Straight terminal plane $60.5 \%$, distal step $3.3 \%$, mesial step $36.3 \%$. Class 1,2 , and 3 canine relationships were $78 \%, 4 \%$, and $18 \%$, unilateral and bilateral posterior crossbite were $3.3 \%$ and $0 \%$,Primate spacing was found in $75.3 \%$ of the population. Overjet $>3 \mathrm{~mm}$ was registered in $3.8 \%$, openbite in $2.0 \%$, and overbite $>3 \mathrm{~mm}$ in $6.8 \%$ of the preschool children.

Conclusion: Flush terminal plane, class I canine relation, ideal overjet, ideal overbite, and spaced arches prevailed among the majority of the study population without any gender variations or variations in the urban and rural areas of Amritsar city.

Keywords: Canine relation, Crossbite, Molar relation, Occlusal characteristics, Primary dentition.

How to cite this article: Sadana G, Mehra M, Grover R, Gupta S, Bhargawa A. Assessment of Occlusal Characteristics in Primary Dentition of Preschool Children in Amritsar, Punjab, India. Curr Trends Diagn Treat 2018;2(1):15-21.

\section{Source of support: Nil}

\section{Conflict of interest: None}

\footnotetext{
${ }^{1}$ Professor and Head, ${ }^{2,3}$ Reader, ${ }^{4}$ Professor, ${ }^{5}$ Junior Resident

${ }^{1-5}$ Department of Paedodontics, Sri Guru Ram Das Institute of Dental Sciences, Amritsar, Punjab, India

Corresponding Author: Gunmeen Sadana, Professor and Head, Department of Paedodontics, Sri Guru Ram Das Institute of Dental Sciences, Amritsar, Punjab, India, e-mail: drgunmeen_sadana@yahoo.in
}

\section{INTRODUCTION}

Today's society dictates norms of acceptable, healthy and attractive look. Millions of individuals worldwide are suffering from orodental problems in spite of most of them were preventable. Malocclusions feature the third highest prevalence among oral pathologies, second only to tooth decay and periodontal disease and therefore rank third among worldwide dental public health priorities. ${ }^{1}$ Malocclusion is not a disease but a morphological variation which may or may not be associated with pathological conditions. The prevalence of malocclusion in India varies from 20 to $43 \%$.

Even though malocclusions do not present lifethreatening conditions but their high prevalence puts them in the focus of public healthcare. Much expressed forms of malocclusions can create a feeling of marginalization and social rejection what could cause negative consequences for individual social integrity. ${ }^{2}$

The need for orthodontic treatment is rising in the majority of countries, which requires rational planning of resources and treatment priorities on whole population level. This fact shows the importance of epidemiological studies to provide information about the prevalence of different types of malocclusions and a real need for orthodontic treatment. ${ }^{3}$

Since childhood is the mirror in which the propensities of adulthood are reflected; similarly the type of occlusion in primary dentition predicts the occlusion of the permanent dentition. The characteristic set of features in primary dentition to a large extent lays the foundation for proper eruption and alignment of the succeeding dentition. ${ }^{4}$

Foster and Hamilton reported the wide variety of occlusion condition in the deciduous dentition, which appears to indicate that these are not fixed but flexible attribute whose aspects should be considered in epidemiological investigations. ${ }^{5}$

Based on the observation of these key features i.e., terminal molar relationship, canine relationship, anterior overjet and overbite and presence of spaced arches in the child's dentoalveolar system during the formative years, the characteristics of the permanent dentition/occlusion can be predicted very well. The correctly placed teeth in dental arch aid in sustaining the better health of the oral cavity and the supporting structures. Malocclusion not only compromises maintaining better hygiene and the 
health of investing tissue but can also lead to behavioral (psychological) and social problems.

Morphological variations in primary dentition are of great concern to a pediatric dentist as they may pose clinical problems associated with them, including dental caries, delayed exfoliation, anomalies in the permanent dentition, such as impaction of successors, supernumerary teeth, permanent double teeth, or aplasia of teeth. ${ }^{6}$ Proper occlusion of teeth is important for many oral functions including mastication, swallowing, speech as well as respiration. Therefore, it is particularly important to have sufficient knowledge regarding the normal occlusion prevalence in primary dentition.

The prevalence of all malocclusions in the primary dentition is not thoroughly reported. Analysis of the occlusion in the primary dentition should consider the arrangement of deciduous teeth and the occlusal relationship of the anterior and posterior segments of both arches. The recognition of normal occlusion patterns in primary dentition, as well as the identification of morphologic changes during permanent teeth eruption, is essential. Thus, early diagnosis of these anomalies allows for more comprehensive long-term treatment planning, favorable prognosis, and a less extensive interception. ${ }^{8}$

Because of the limited number of studies pertaining to occlusion in preschool children and the contradictory findings concerning age changes in deciduous molar relation, a further investigation seemed appropriate. The present study enrolled 1200 children having age 3 to 5 years, attending public and private preschool in Amritsar. The objectives of this study were to assess the characteristic features of occlusion in primary dentition with the following parameters:

1. To assess the terminal molar relations

2. To assess the canine relations

3. To assess the presence of any anterior or posterior cross-bite.

\section{MATERIALS AND METHODS}

This cross-sectional study was conducted among a total of 1200 preschool children having age 3 to 5 years in urban and rural areas of Amritsar, Punjab. Ethical clearance was sought from the ethics committee of Sri Guru Ram Das College of Dental Sciences and Research, Amritsar, after explaining the aim and importance of the study. A stratified cluster random sampling method was used to select children from the schools. The age of the child was obtained from school records.

\section{Inclusion Criteria}

- Children aged less than 5 years of age.

- Complete set of primary teeth.

- Presence of spaced and non-spaced dentition.

\section{Exclusion Criteria}

- The eruption of any permanent first molar/incisor tooth

- The grossly decayed tooth (that affected the mesiodistal and occlusogingival dimension of teeth)

- Missing teeth due to caries or any other reason

- Teeth with developmental anomalies.

The children were examined in their respective schools by a single examiner under natural daylight, and the data was recorded on a specially prepared proforma. The intra-examiner reliability test was performed by examining a cohort of 25 children at two different time periods of 1 week apart, and the Kappa statistic accounted to $93 \%$. The primary molar relation, canine relation, overjet, and overbite were assessed using Foster and Hamilton criteria with the teeth in centric occlusion.

Terminal plane relationship of the second primary molars was evaluated and recorded as:

Flush Terminal Plane: The distal surfaces of maxillary and mandibular primary second molars lie in the same vertical plane;

Distal Step Molar Relation: The distal surface of the mandibular primary second molar is posterior to that of maxillary primary second molar.

Mesial step molar relation: The distal surface of the mandibular primary second molar is anterior to that of the maxillary primary second molar.

The primary canine relationship was evaluated and recorded as:

Class 1: The tip of the maxillary primary canine tooth is in the same vertical plane as the distal surface of the mandibular primary canine.

Class 2: The tip of the maxillary primary canine tooth is mesial to the distal surface of the mandibular primary canine.

Class 3: The tip of maxillary primary canine is distal to the distal surface of the mandibular primary canine.

Overjet was measured as the most significant distance between the incisal edges of the maxillary and mandibular primary incisors in the occlusal plane using a millimeter gauge and recordee:

Ideal: If overjet is less than or equal to $2 \mathrm{~mm}$.

Increased: If it is greater than $2 \mathrm{~mm}$.

Reversed: If there is an anterior cross-bite and edge-to-edge relationship was also assessed.

Vertical occlusion was graded according to the coverage of mandibular incisor by the most protruded fully erupted maxillary incisor and was recorder:

Ideal: If the lower primary incisal edges are contacting the palatal surfaces of the upper primary central incisors in centric occlusion. 
Increased: If the mandibular incisors are touching the palate, open bite, when a gap existed between the incisal edges of incisors along the occlusal plane.

Reduced: If the incisal tips of the lower primary incisors are not contacting the palatal surface of the upper incisors or the palate in centric occlusion but with the positive overbite.

\section{Statistics}

Chi-square test was used to compare the variables assessed within the population. For all analyses, a p-value of $\leq 0.05$ was set for statistical significance, and a p-value of $\leq 0.001$ represented a highly significant relation.

\section{RESULTS}

Data from the study conducted in Amritsar showed a sample of 1200 preschool children, $53.3 \%$ boys and $46.8 \%$ girls, $50 \%$ of the sample derived from urban areas and another $50 \%$ of rural regions of Amritsar.

Frequencies and proportions of molar and canine relationships were analyzed.

Considering values from both sides, the relationships of the second deciduous molars were: straight terminal plane $60.5 \%$, distal step 3.3\%, mesial step 36.3\% (Table 1). There was statistically no significant difference $(P=0.254)$ in the molar relation among males and females (Table 2), (Fig. 1) and in rural and urban (Table 3) preschool children $(\mathrm{p}=0.638)$.

The frequencies of Class 1 to 3 canine relationships were 78, 4, and 18\% respectively (Table 2 and Fig. 2). Confidence intervals (95\%) for the prevalence values of canine relationships did not indicate statistically significant differences between canine relationships in urban and rural areas (Table 3) $(p=0.187)$.

Prevalence rates of unilateral and bilateral posterior crossbite were $3.3 \%$ and $0 \%$, respectively (Table 1 and Fig. 3).

Spaced arches were found in approximately $46.3 \%$ of the sample in both upper and lower dental arches (Table 1). Statistically significant differences were seen in urban and rural areas (Table 3$)(p=0.012)$. Primate spacing was found in $75.3 \%$ of the population.

Overjet $>3 \mathrm{~mm}$ was registered in $3.8 \%$, open bite in $2.0 \%$, and overbite $>3 \mathrm{~mm}$ in $6.8 \%$ of the preschool children (Table 1).

\section{DISCUSSION}

Early recognition of conditions predisposing young children to malocclusions is in the hands of a pediatric dentist, so the early interceptive procedure can be applied by pediatric dentist to prevent further consequences. ${ }^{2}$ Bouge in 1908 stated that if malocclusions were found in the primary dentition, the same occlusal problems would be expected to occur in the succeeding permanent dentition. ${ }^{7}$

The presence of spaced or closed dentition in the primary dentition and its significance for the development of permanent dentition has long been a subject of discussion. There have been many studies of the primary dentition in preschool children in several ethnic groups. However, the ages of children examined ranged from 2.5 to 5 years. Bishara et al. reported that the

Table 1: Prevalence of occlusal characteristics in children of Amritsar

\begin{tabular}{llll}
\hline Occlusal parameter & Type & Number $(n)$ & Percentage (\%) \\
\hline Occlusal relationship & Flush terminal & 726 & 60.5 \\
& Mesial step & 435 & 36.3 \\
& Distal step & 39 & 3.3 \\
Canine relationship & Class 1 & 936 & 78 \\
& Class 2 & 48 & 4.0 \\
Anterior overjet & Class 3 & 216 & 18.0 \\
& Positive & 1194 & 99.5 \\
Anterior overbite & Negative & 6 & 0.5 \\
& Increased overjet & 45 & 3.8 \\
Posterior cross bite & Positive & 1176 & 98 \\
& Anterior open bite & 24 & 2 \\
Generalised spacing & Deep bite & 81 & 6.8 \\
& Unilateral & 39 & 3.3 \\
Primate spacing & Bilateral & 0 & 0.0 \\
& Absent & 1161 & 96.8 \\
& Present & 555 & 46.3 \\
\hline
\end{tabular}


Table 2: Comparison of occlusal characteristics in males v/s females

\begin{tabular}{|c|c|c|c|c|c|c|}
\hline \multirow[b]{2}{*}{ Occlusal parameter } & \multirow[t]{2}{*}{ Type } & \multicolumn{2}{|c|}{ Male } & \multicolumn{2}{|c|}{ Female } & \multirow[b]{2}{*}{ p-value } \\
\hline & & $n$ & $\%$ & $n$ & $\%$ & \\
\hline \multirow[t]{3}{*}{ Occlusal relationship } & Flush terminal & 408 & 63.80 & 318 & 56.70 & $0.254 \mathrm{NS}$ \\
\hline & Mesial step & 216 & 33.80 & 219 & 39.00 & \\
\hline & Distal step & 15 & 2.30 & 24 & 4.30 & \\
\hline \multirow[t]{3}{*}{ Canine relationship } & Class 1 & 504 & 78.9 & 432 & 77.0 & $0.435 \mathrm{NS}$ \\
\hline & Class 2 & 18 & 2.8 & 30 & 5.3 & \\
\hline & Class 3 & 117 & 18.3 & 99 & 17.6 & \\
\hline \multirow[t]{3}{*}{ Anterior overjet } & Positive & 636 & 99.5 & 558 & 99.5 & $0.926 \mathrm{NS}$ \\
\hline & Negative & 3 & 0.5 & 3 & 0.5 & \\
\hline & Increased overjet & 27 & 4.2 & 18 & 3.2 & \\
\hline \multirow[t]{3}{*}{ Anterior overbite } & Positive & 618 & 98.54 & 558 & 99.46 & $0.128 \mathrm{NS}$ \\
\hline & Anterior open bite & 21 & 3.3 & 3 & 0.5 & \\
\hline & Deep bite & 39 & 6.1 & 42 & 7.5 & \\
\hline \multirow[t]{3}{*}{ Posterior cross bite } & Unilateral & 24 & 3.8 & 15 & 2.7 & $0.543 N S$ \\
\hline & Bilateral & 0 & & 0 & & \\
\hline & Absent & 615 & 96.2 & 546 & 97.3 & \\
\hline \multirow[t]{2}{*}{ Generalised spacing } & Present & 279 & 43.7 & 276 & 49.2 & $0.268 \mathrm{NS}$ \\
\hline & Absent & 360 & 56.3 & 285 & 50.8 & \\
\hline \multirow[t]{2}{*}{ Primate spacing } & Present & 489 & 76.5 & 414 & 73.8 & $0.528 \mathrm{NS}$ \\
\hline & Absent & 150 & 23.5 & 147 & 26.2 & \\
\hline
\end{tabular}

NS: $p>0.05$; Not significant; ${ }^{*} p<0.05$; Significant

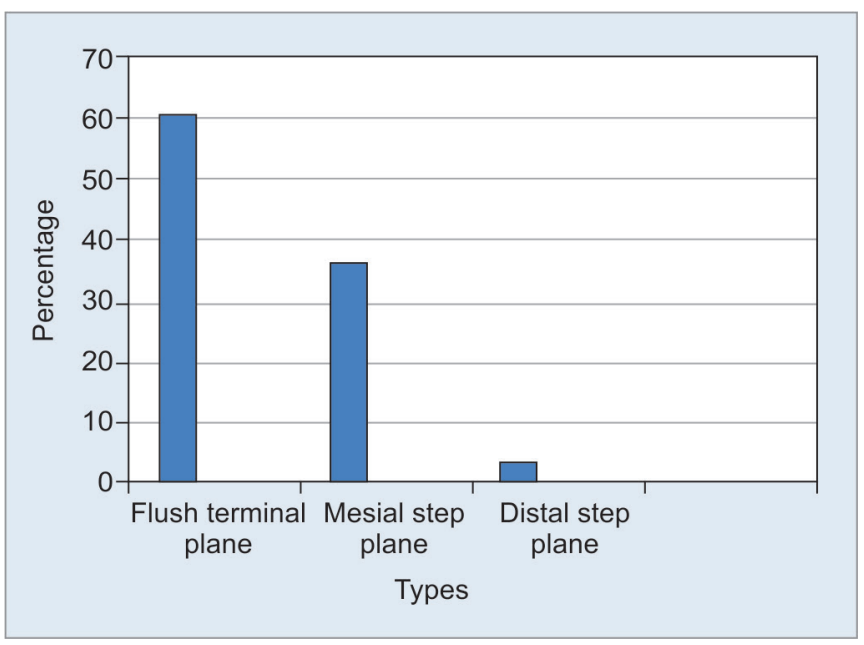

Fig. 1: Prevalence of molar relation

maxillary and mandibular intercanine and intermolar widths significantly increase between 3 and 5 years of age. Therefore, the subjects in this study were limited to those below 6 years of age. ${ }^{9}$

The occlusion of the primary dentition is completely established by the age of 3 years and lasts until about 6 years of age when the first permanent tooth begins to erupt. Understanding the association between morphological aspects in the primary dentition and its transition to the permanent dentition provides the possibility of predicting the final permanent occlusion.

The most predominant primary molar relation followed by mesial and distal steps, and a similar trend was noticed in our study; Flush terminal plane $(60.5 \%)$, distal step (3.3\%), mesial step (36.3\%) (Fig.1).

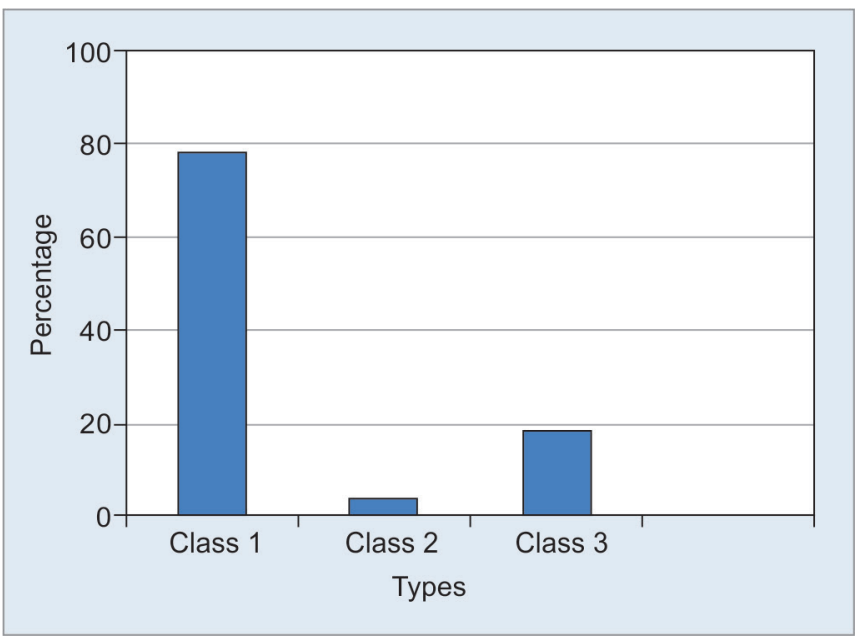

Fig. 2: Prevalence of canine relation

The findings of our study were similar to a study conducted by Deepak P Bhayya 2012 in India-the study showed that the majority of the children in the sample had a flush terminal molar relationship (52.5\%), followed by mesial step $(36 \%)$ and distal step $(8.4 \%)$ and Class I canine relationship with $84 \%{ }^{10}$

Results were also similar to a study conducted Khan R in 2014 in North Indian school-going children of East Lucknow region, revealing $62.3 \%$ had a flush terminal plane; $31.3 \%$ mesial step molar relationship and $6.4 \%$ distal step molar relationship. ${ }^{11}$

The flush terminal plane was found to be the most common molar relation and considered ideal for the transition to Class I in permanent dentition. However, the mesial step was found to be normal for completed 
Table 3: Comparison of occlusal characteristics in rural vs. urban population

\begin{tabular}{|c|c|c|c|c|c|c|}
\hline \multirow[b]{2}{*}{ Occlusal parameter } & \multirow[t]{2}{*}{ Type } & \multicolumn{2}{|r|}{ Male } & \multicolumn{2}{|c|}{ Female } & \multirow[b]{2}{*}{$p$-value } \\
\hline & & $n$ & $\%$ & $n$ & $\%$ & \\
\hline \multirow[t]{3}{*}{ Occlusal relationship } & Flush terminal & 351 & 58.5 & 375 & 62.5 & $0.638 \mathrm{NS}$ \\
\hline & Mesial step & 231 & 38.5 & 204 & 34.0 & \\
\hline & Distal step & 18 & 3.0 & 21 & 3.5 & \\
\hline \multirow[t]{3}{*}{ Canine relationship } & Class 1 & 489 & 81.5 & 447 & 74.5 & $0.187 \mathrm{NS}$ \\
\hline & Class 2 & 24 & 4.0 & 24 & 4.0 & \\
\hline & Class 3 & 87 & 14.5 & 129 & 21.5 & \\
\hline \multirow[t]{3}{*}{ Anterior overjet } & Positive & 600 & 100.0 & 594 & 99.0 & $0.156 \mathrm{NS}$ \\
\hline & Negative & 0 & 0 & 6 & 1.0 & \\
\hline & Increased overjet & 18 & 3.0 & 27 & 4.5 & \\
\hline \multirow[t]{3}{*}{ Anterior overbite } & Positive & 588 & 98 & 588 & 98 & $0.983 N S$ \\
\hline & Anterior open bite & 12 & 2.0 & 12 & 2.0 & \\
\hline & Deep bite & 39 & 6.5 & 42 & 7.0 & \\
\hline \multirow[t]{3}{*}{ Posterior cross bite } & Unilateral & 18 & 3.0 & 21 & 3.5 & $0.778 \mathrm{NS}$ \\
\hline & Bilateral & 0 & 0 & 0 & 0 & \\
\hline & Absent & 582 & 97.0 & 579 & 96.5 & \\
\hline \multirow[t]{2}{*}{ Generalised spacing } & Present & 315 & 52.5 & 240 & 40.0 & $0.012^{*}$ \\
\hline & Absent & 285 & 47.5 & 360 & 60.0 & \\
\hline \multirow[t]{2}{*}{ Primate spacing } & Present & 474 & 79.0 & 429 & 71.5 & $0.082 \mathrm{NS}$ \\
\hline & Absent & 126 & 21.0 & 171 & 2.5 & \\
\hline
\end{tabular}

NS: $p>0.05$; Not significant; ${ }^{*} p<0.05$; Significant

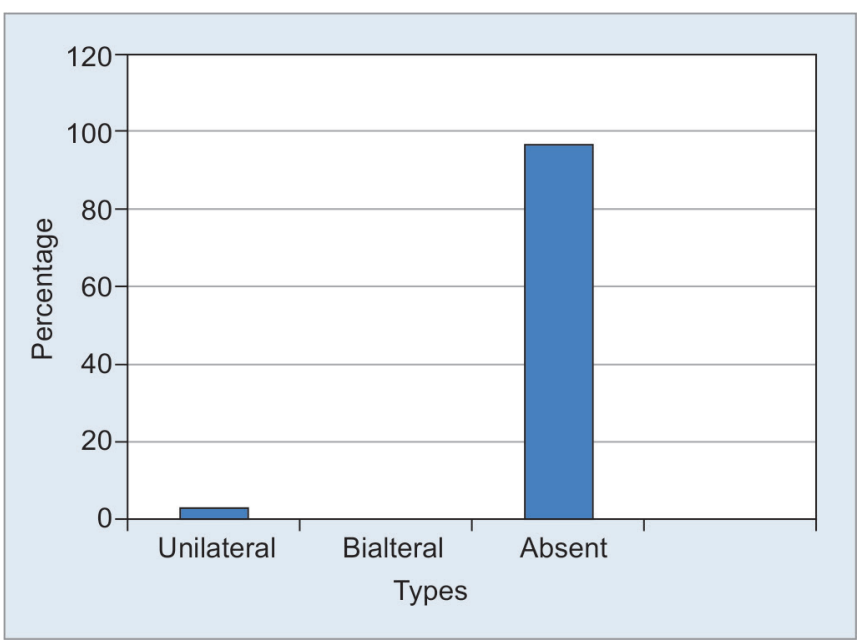

Fig. 3: Prevalence of cross-bite

primary dentition rather than flush terminal plane. The magnitude of mesial step determines whether it would result in Angle's Class I or Class III molar relationship. Since the flush terminal plane was the most common molar relationship in the present study, we anticipate that the majority of the sample may have a favorable permanent molar relation.

The findings of the present study showed that $78 \%$ had Class I canine relationship, $4.0 \%$ had Class II, and $18 \%$ had Class III (Fig. 2). These findings were similar to the previous study by Khan R in 2014 in North Indian school-going children of East Lucknow region; it was observed that $91.6 \%$ had Class I canine relationship. ${ }^{11}$

The finding of our study is similar with the study done by Yilmaz Y et al., in 2006 who observed occlusal relationship in primary canine which was found to be Class I with the rate of $87.8 \%$ in all age groups. The Class II relationship followed with a $7.8 \%$ frequency rate and three to four-year-old groups demonstrated no Class III primary canine relationship. ${ }^{12}$

Canine and molar relationship together can be a diagnostic aid to predict changes in the occlusal relationship. In clinical situations like a flush terminal plane with Class II canine relationship indicates a higher risk to develop a distal occlusion in permanent dentition. Therefore both the molar and canine relationships are taken into consideration to make a reliable prediction of the intermaxillary relationship in the permanent dentition.

The results of our study also showed that bilateral molar and canine relationships were not significantly different among the children of urban and rural areas.

The results of our investigation revealed positive overjet in $99.5 \%$ children, increased overjet in $3.8 \%$, and reversed overjet in $0.5 \%$ of the children (Fig. 3).

This finding was consistent with the study of Madhuri Vegesna et al., 2014 who demonstrated ideal overjet in $84.3 \%$, increased overjet in $8.9 \%$, and reverse bite in $1.7 \%{ }^{3}$

The findings were also similar to a study conducted by Sapna Hegde in 2012 in Udaipur, anterior crossbite relationship was observed only in $0.5 \%$ children. ${ }^{13}$

On the contrary, Foster and Hamilton found increased overjet in $72 \%$ of $21 / 2$ to 3 -year-old children and Ravn reported increased overjet in $27 \%$ of Copenhagen children. ${ }^{14}$ 
A positive overbite was found in $98 \%$ of children $6.8 \%$ had increased bite, and $2 \%$ had an anterior open bite.

A study by Deepak P Bhayya (2012) in India also showed anterior open bite was scant in population $(1 \%)$ and the majority of the children $(94.4 \%)$ studied showed the overbite between 0 to $2 \mathrm{~mm} .{ }^{10}$

Deep bite in $7 \%$ of the preschool children was also seen in a study conducted by Eliete Rodrigues de Almeida in $2008{ }^{4}$

The increased open bite could be attributed to oral habits such as dummy sucking and finger sucking. Attention should be given to the interpretation of these rates, considering that deep overbite generally interferes in opening, protrusion, and lateral movements and is potentially hazardous to the temporomandibular joint when transferred to the permanent dentition and negative overbite (open bite) appears to be the only malocclusion expected to decrease in the transition to the permanent dentition.

Likewise, attention should be given to the posterior crossbite in the deciduous dentition. Unilateral posterior crossbite was found in 3.3\% of children in our study.

Anterior crossbite, posterior crossbite is surly were rare malocclusion traits ( $1.9 \%$ and $0.6 \%$, respectively) in the study group of Deepak P Bhayya in 2012 in Indian children. ${ }^{10}$

Anterior crossbite relationship was observed only in $0.5 \%$ children; Posterior crossbite was not observed in a study population of Sapna Hegde (2012). ${ }^{13}$

It is believed that a posterior crossbite is transferred from the deciduous to the permanent dentition with long-term effects on the growth and development of the teeth and jaws, and even craniofacial asymmetry. Impaired nasal breathing caused by enlarged tonsils and adenoids are also related to posterior crossbites and can be diagnosed early.

Spaces in the primary teeth are described as physiological or developmental spaces. The spacing around the canines is termed as the simian gap, primate space, or anthropoid space since they are prominent in dentitions of certain lower primates. Based on the spacing between the teeth, Baume has classified the arrangement of primary dentition into two forms: open and closed.

Anterior spacing appears to be a common finding in our study population. Primate spaces were frequently found in the maxilla and mandible in the present study (75.3\%).

Leighton's hypothesis suggests that there should be $6 \mathrm{~mm}$ or more space between mandibular teeth for there to be no chance of developing incisor crowding in permanent dentition. ${ }^{14}$

The findings of our study were consistent with studies in Tehran and Saudi, where primate spaces did not show a significant difference between the genders. Whereas significant results were found in generalized spacing in rural and urban areas $(p=0.01) .{ }^{15}$
Finding of our study is similar to the study done by Sahaf et al. in 2005-which concluded that the spaced type of the dental arch occurred more frequently than the closed type in both upper and lower arches and specially in an urban area reason being the highly educated parent in the urban population while in rural area the observation has similar distribution of both spaced and closed dentition. ${ }^{16}$

The present study provided insight into the state of dentition, occlusal pattern, and spacing and crowding in the primary dentition of Indian children of Amritsar. Although the results suggest a low prevalence of malocclusion in the primary dentition of this population, further studies on a larger sample of the same population are warranted.

\section{CONCLUSION}

This study provides information of prevalence of spacing and closed dentition Flush terminal plane, class I canine relation, ideal overjet, ideal overbite among the majority of the study population without any gender variations or variations in the urban and rural areas of Amritsar city. These findings suggest desirable occlusal characteristics and spacing in primary dentition. However, future longitudinal studies are needed to observe whether the transition of these occlusal characteristics will lead to favorable occlusion in the permanent dentition.

\section{REFERENCES}

1. Redžepagić Vražalica L, Ilić Z, Laganin S, Džemidžic V, Tiro A. An epidemiological study of malocclusion and occlusal traits related to different stages of dental development. South European journal of orthodontics and dentofacial research. 2017 Apr 27;4(1):9-13.

2. Shavi GR, Hiremath NV, Shukla R, Bali PK, Jain SK, Ajagannanavar SL. Prevalence of spaced and non-spaced dentition and the occlusal relationship of primary dentition and its relation to malocclusion in school children of Davangere. Journal of international oral health: JIOH. 2015 Sep; 7(9):75

3. Vegesna M, Chandrasekhar R, Chandrappa V. Occlusal characteristics and spacing in primary dentition: a gender comparative cross-sectional study. International scholarly research notices. 2014;2014

4. Yadav NR, Prasad S, Rajashekharappa CB, Tandon S. Gender influence on occlusal characteristics in the primary dentition. APOS Trends in Orthodontics. 2014 Jul 1;4(4):87.

5. Almeida ER, Narvai PC, Frazão P, Guedes-Pinto AC. Revised criteria for the assessment and interpretation of occlusal deviations in the deciduous dentition: a public health perspective. Cadernos de saude publica. 2008 Apr;24(4):897-904.

6. Lochib S, Indushekar KR, Saraf BG, Sheoran N, Sardana D. Occlusal characteristics and prevalence of associated dental anomalies in the primary dentition. Journal of epidemiology and global health. 2015 Jun 1;5(2):151-157. 
7. Fernandes S, PatelDG, Ranadheer E, Kalgudi J, SantokìJ, Chaudhary S. Occlusal traits of primary dentition among pre-school children of Mehsana District, North Gujarat, India. Journal of clinical and diagnostic research: JCDR. 2017 Jan;11(1):ZC92.

8. Bhat SS, Rao HA, Hegde KS, Kumar BK. Characteristics of primary dentition occlusion in preschool children: An epidemiological study. International journal of clinical pediatric dentistry. 2012 May;5(2):93.

9. Vinay S, Keshav V, Sankalecha S. Prevalence of spaced and closed dentition and its relation to malocclusion in primary and permanent dentition. International journal of clinical pediatric dentistry. 2012 May;5(2):98.

10. Bhayya DP, Shyagali TR, Dixit UB. Study of occlusal characteristics of primary dentition and the prevalence of maloclusion in 4 to 6 years old children in India. Dental research journal. 2012 Sep;9(5):619-623.

11. Khan R, Singh N, Govil S, Tandon S. Occlusion and occlusal characteristics of primary dentition in North Indian children of East Lucknow region. European Archives of Paediatric Dentistry. 2014 Oct 1;15(5):293-299.

12. Yilmaz Y, Gurbuz T, Simsek S, Dalmis A. Primary canine and molar relationships in centric occlusion in three to six yearold Turkish children: a cross-sectional study. J Contemp Dent Pract. 2006 Jul 1;7(3):59-66.

13. Hegde S, Panwar S, Bolar DR, Sanghavi MB. Characteristics of occlusion in primary dentition of preschool children of Udaipur, India. European journal of dentistry. 2012 Jan;6(1): 51-55

14. Foster TD, Hamilton MC. Occlusion in the primary dentition. British Dental Journal 1969;126(2):76-79.

15. Farsi N, Salma FS. Characteristics of primary dentition occlusion in a group of Saudi children. International journal of paediatric dentistry. 1996 Dec 1;6(4):253-259.

16. Al-Sahaf NH. Spacing in the Normal Deciduous Dentition among Urban and Rural Children in Baghdad Province. IOJIraqi Orthodontic Journal. 2005:13-17. 